\title{
Sonographic diagnosis of heterotopic bone formation in spinal injury patients
}

\author{
V N Cassar-Pullicino LRCP MRCS DMRD MD FRCR, ${ }^{1} \mathrm{M}$ McClelland BSC MB BcH \\ BAO FRCS, ${ }^{2}$ D A H Badwan MB ChB, FRCS, ${ }^{2}$ I W McCall MB ChB DMRD FRCR, ${ }^{1}$ \\ RG Pringle MB ChB FRCR, ${ }^{2}$ W El Masry MB BcH FRCS ${ }^{2}$ \\ ${ }^{1}$ Department of Diagnostic Imaging, ${ }^{2}$ Midland Centre for Spinal Injuries, The Institute of \\ Orthopaedics, The Robert Jones \& Agnes Hunt Orthopaedic Hospital, Oswestry, \\ Shropshire, SY10 7AG, England.
}

\begin{abstract}
A variety of stimuli including neurological insult may provoke primitive mesenchymal cells to differentiate into bone forming cells. Such a sequel following spinal cord injury can delay rehabilitation, enhance the spasticity and reduce the range of movement in the affected joint. It is characterised by an initial inflammatory phase followed by heterotopic bone formation. The early inflammatory lesion clinically mimics deep vein thrombosis, a developing pressure sore, infection, and tumour. An early diagnosis at a time of clinical uncertainty, before the plain radiographic features develop, has distinct advantages and therapeutic implications.

The unique pathological evolution and maturation of the lesion is clearly demonstrated by sequential sonographic (ultrasonic) assessment with depiction of the 'zone phenomena' seen on histology. Sonographic scans in 7 spinal injury patients proved diagnostic, before there was radiographic evidence of bone formation, and confidently excluded $\mathrm{HBF}$ in a further 18 patients without any false negative results.
\end{abstract}

Keywords: sonography; heterotopic bone formation; myositis ossificans; spinal injury.

\section{Introduction}

Heterotopic bone formation (HBF) is a well known complication following traumatic spinal cord injury. ${ }^{1,2}$ The natural history of $\mathrm{HBF}$, described pathologically, has a predictable temporal sequence which incorporates the formation of 'zone phenomena' as the lesion matures. ${ }^{3,4}$ The aim of this prospective study was to assess the place of sonography in defining this unique evolutionary pattern before radiographic confirmation and to determine its sensitivity and specificity, in a prospective study of 25 spinal injury patients with limb swelling.

\section{Materials and methods}

During a 3 year period, 25 patients referred to the imaging department with non specific limb inflammation following spinal cord injury were evaluated with sonography and radiological examinations. In 23 patients sonography was the first investigation performed within 24 hours of presentation and 2 patients had sonographic assessment after negative venography. The whole affected lower limb up to the iliac crest was examined with simultaneous comparative assessment of the contralateral limb. The 18 patients in whom an alternative diagnosis was made were eliminated from further sonographic examination (Table I). Subsequent radiological follow up in these cases confirmed the absence of HBF over a 3-6 month period. In the remaining 7 patients serial sonographic examinations were performed at weekly intervals utilising a 3.5 Megahertz and/or a 7.5 Megahertz transducer probe. Plain radiographs were obtained to determine the temporal relationship between the evolving sonographic appearances, and radiographic features of calcification and ossification. The imaging 
Table I Cause of limb swelling (25 patients)

\begin{tabular}{ll}
\hline Heterotopic bone formation & 7 \\
Venous thrombosis & 3 \\
Infection & 3 \\
Sudeck's atrophy & 3 \\
Pressure sore & 2 \\
Unrecognised bone injury & 1 \\
Unknown & 6 \\
\hline
\end{tabular}

abnormalities were correlated with clinical and biochemical data including serum alkaline phosphatase levels before, during and after presentation.

\section{Results}

Seven patients developed the classic radiographic features of mature heterotopic bone formation (HBF) (Fig 1). All lesions were paraarticular involving the hip and trochanteric region (4 patients), the elbow joint ( 2 patients), and the shoulder joint (1 patient). In none of these instances was a clinical diagnosis made. The time interval between the spinal cord injury and presentation of limb swelling ranged between 6 to 26 weeks with a mean of 12 weeks. There were no cases with bilateral involvement. Details of the level of injury and associated neurological deficit are presented in Table II. All the upper limb lesions were associated with direct peripheral trauma besides cervical spine injury. None of the lower limb lesions had associated peripheral skeletal trauma.

Plain radiographic features diagnostic of HBF appeared at 4 to 6 weeks after presentation in all 7 cases (Figs 1,2,3). The sonographic appearances depended entirely on the age of the lesion, and the degree of mineralisation. In the initial examination a thin echo-lucent zone (1) of the surrounding muscle enclosed a broader highly reflective zone (2) which in turn surrounded an amorphous echo-lucent zone (3) (Figs 2, 4, $5)$. Zone (2) was not uniformaly reflective in the early lesion but contained foci of echogenic islands which rapidly became confluent (Fig 4,5). As the lesion matured the more peripheral rim of this zone (2) became increasingly reflective due to increased mineralisation and coincided with the radiographic demonstration of faint non specific floccular calcification (Figs 2,4). Further consolidation resulted in the total reflection of the sonographic beam as the maturing periphery of the HBF lesion behaved as corticated bone (Figs 2, 4). At this stage plain films became diagnostic of $\mathrm{HBF}$, which was consistently between 4 to 6 weeks after clinical presentation of limb inflammation. In all of the patients the process of maturation defined sonographically was identical. The 'zone phenomena' were present at clinical presentation, reproduced in all cases, and disappeared with maturation as the well corticated periphery reflected the sonic beam. There were no false negative sonographic examinations based on follow up radiographs in the remaining 18 patients where the sonographic pattern of 'zone phenomenon' was absent, and no subsequent HBF developed, thus indicating a maximum sensitivity and specificity.

Lower limb venography performed in 6 patients demonstrated venous thrombosis in 3 while in 2 of the 3 cases with normal venography, extrinsic venous compression by unossified $\mathrm{HBF}$ was noted which was recognised sonographically (Fig 2, 5). Sonography demonstrated infection with abscess cavities in 2 patients while radiographic follow up in 4 patients demonstrated Sudeck's atrophy (3 patients) and unrecognised tarsal fractures (one patient). In 6 patients the lower limb swelling subsided rapidly in a few days with negative sonographic and radiological results and no specific diagnosis being made. Serum alkaline phosphatase (SAP) estimations were available before and after sonographic detection of HBF (Table II). The average time interval in the follow up period varied in the individual cases, but in all cases serial estimations were available in the first 6 months after HBF detection. Given a normal SAP range of 45-125 U/L, Table II shows that 3 patients had abnormally increased levels after sonography, but in no patient was the alkaline phosphatase level increased before sonographic diagnosis. Four patients had estimations consistently within the normal range, showing a subsequent increase in the SAP level but not beyond the upper limit of normal. 
a

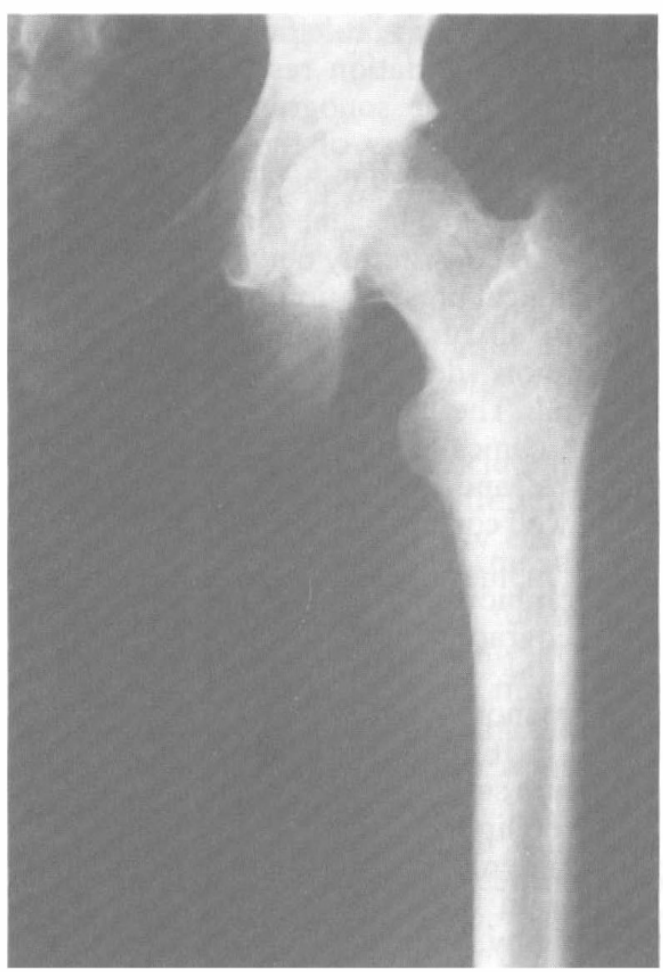

c

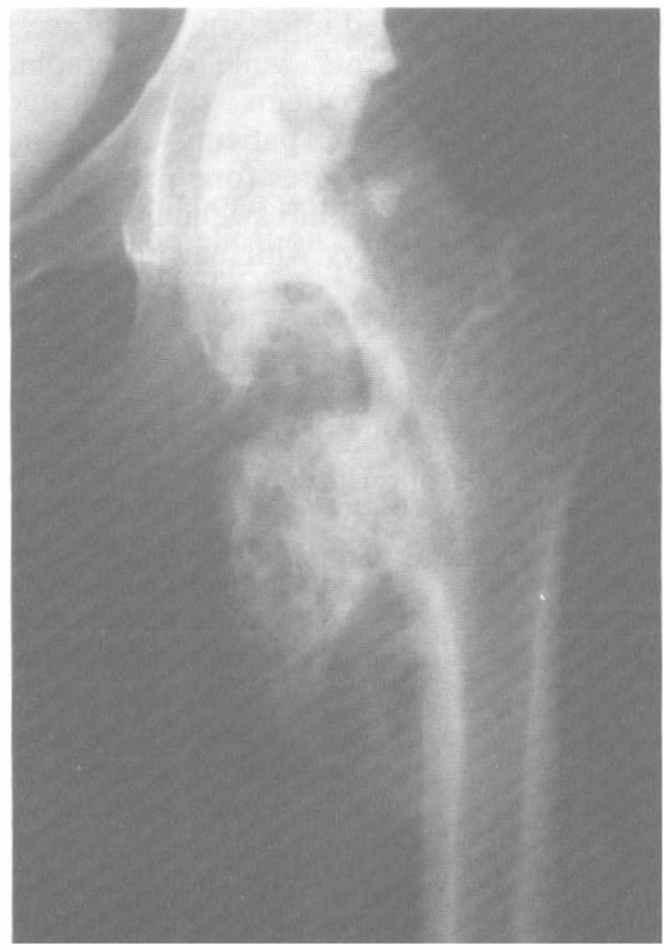

b

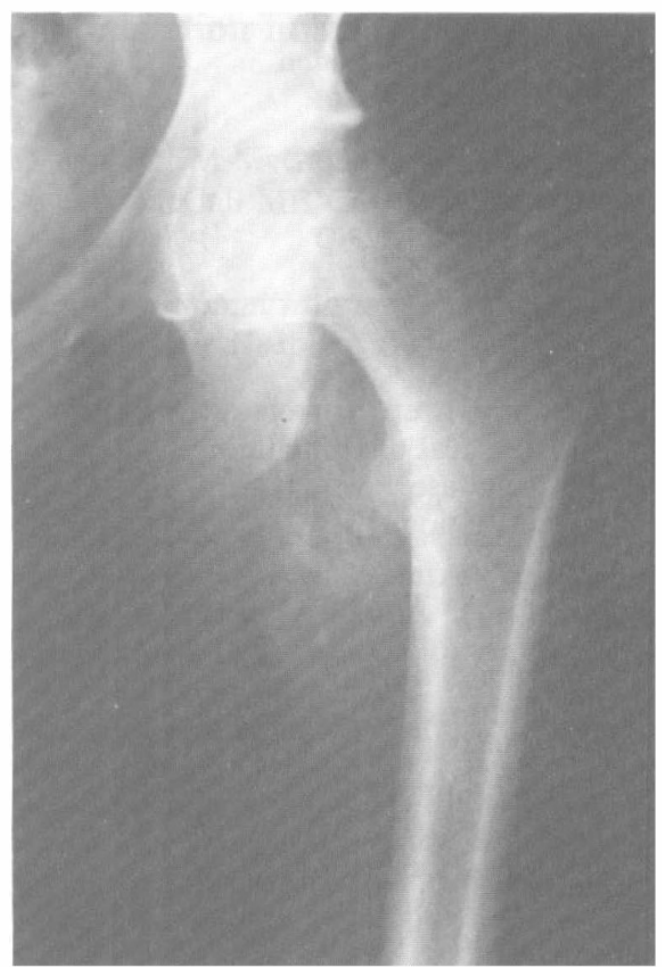

Figure 1 Plain radiographic appearances of HBF (a) 4 weeks after clinical presentation with faint calcification in the soft tissues inferior and medial to the lesser trochanter; (b) at 6 weeks with further mineralisation; and (c) 12 weeks after presentation with mature new bone formation extending proximally to the hip joint. 
Table II Serum alkaline phosphatase (1) and (2) - assessments before and after sonographic HBF detection

\begin{tabular}{|c|c|c|c|c|c|c|c|c|}
\hline Case & Sex & Age & HBF site & Skeletal injury & $\begin{array}{l}\text { Neurological } \\
\text { deficit }\end{array}$ & $\begin{array}{l}\text { Duration before } \\
\text { presentation } \\
\text { (weeks) }\end{array}$ & SAP (1) & SAP (2) \\
\hline 1 & $\mathrm{~F}$ & 62 & Elbow & $\begin{array}{l}\text { Bilat. facet disloca- } \\
\text { tion C6/7 } \\
\text { Elbow dislocation }\end{array}$ & $\begin{array}{l}\text { Brown-Sequard } \\
\text { syndrome }\end{array}$ & 7 & 79 & 77 \\
\hline 2 & $\mathbf{M}$ & 22 & Hip & $\begin{array}{l}\text { C5/C6 unilateral } \\
\text { facet dislocation } \\
\text { T5/T6 fracture dis- } \\
\text { location }\end{array}$ & $\begin{array}{l}\text { T5 complete } \\
\text { paraplegia }\end{array}$ & 26 & 68 & 209 \\
\hline 3 & $\mathbf{M}$ & 24 & Hip & $\begin{array}{l}\text { T8/T9 fracture dis- } \\
\text { location }\end{array}$ & $\begin{array}{l}\text { T9 complete } \\
\text { paraplegia }\end{array}$ & 14 & 12 & 121 \\
\hline 4 & $\mathbf{M}$ & 25 & Hip & $\begin{array}{l}\text { C6 burst fracture } \\
\text { Fracture dislocation } \\
\text { C7/T1 }\end{array}$ & $\begin{array}{l}\text { C7 incomplete } \\
\text { tetraplegia }\end{array}$ & 12 & 65 & 108 \\
\hline 5 & $\mathbf{M}$ & 61 & Hip & $\begin{array}{l}\text { Fracture dislocation } \\
\text { T10/T11 }\end{array}$ & $\begin{array}{l}\text { T9 complete } \\
\text { paraplegia }\end{array}$ & 12 & 106 & 234 \\
\hline 6 & $\mathbf{M}$ & 24 & Shoulder & $\begin{array}{l}\text { Fractures C7, T10, } \\
\text { T12, L1 } \\
\text { Dislocated shoulder }\end{array}$ & $\begin{array}{l}\text { Minimal motor } \\
\text { deficit } \\
\text { No sensory deficit }\end{array}$ & 6 & 103 & 141 \\
\hline 7 & $\mathbf{M}$ & 34 & Elbow & $\begin{array}{l}\text { Fracture C5 } \\
\text { Fractured ulna } \\
\text { + radial head dis- } \\
\text { location }\end{array}$ & $\begin{array}{l}\text { C6 incomplete } \\
\text { tetraplegia }\end{array}$ & 6 & 74 & 70 \\
\hline
\end{tabular}


$\mathbf{a}$

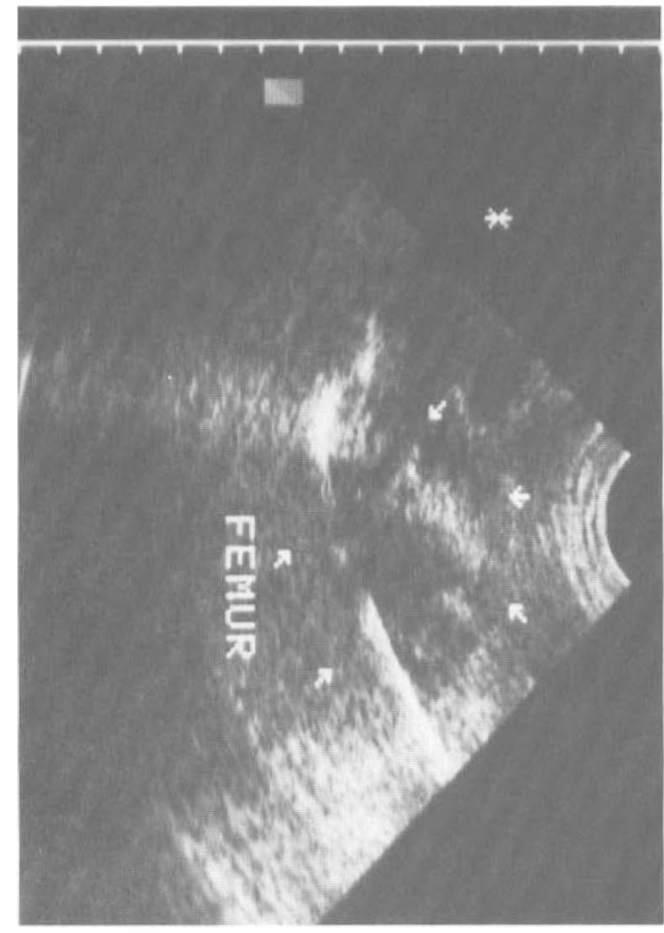

c

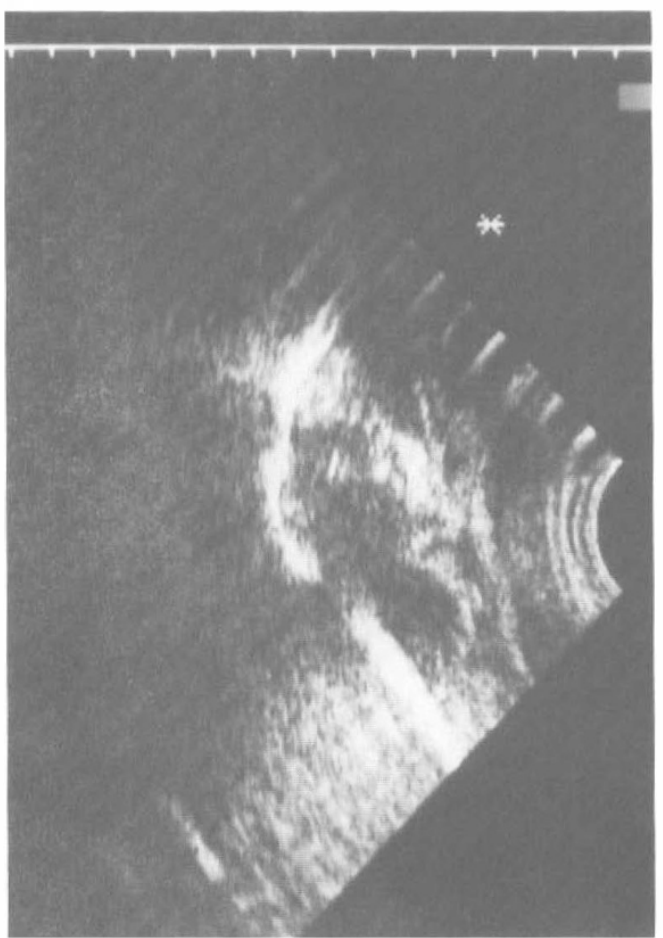

b

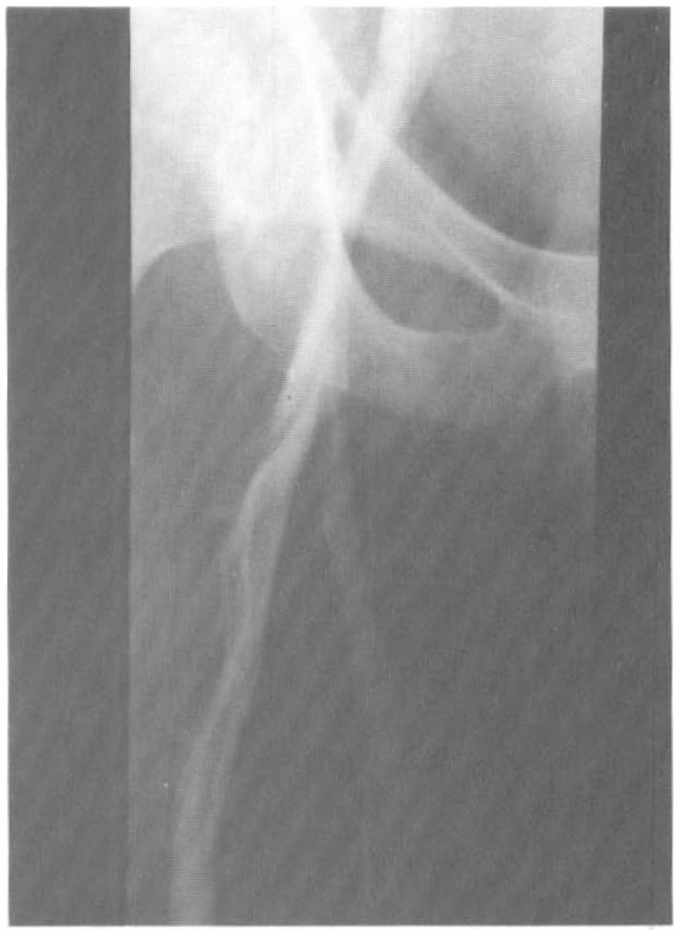

d

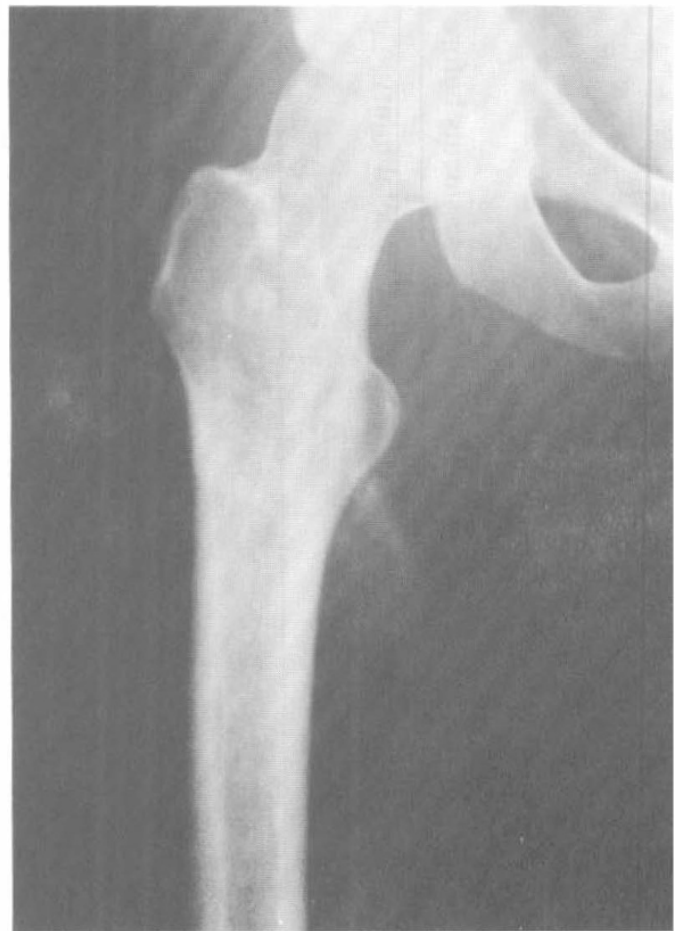

Figure 2 (a-d) Caption on following page. 


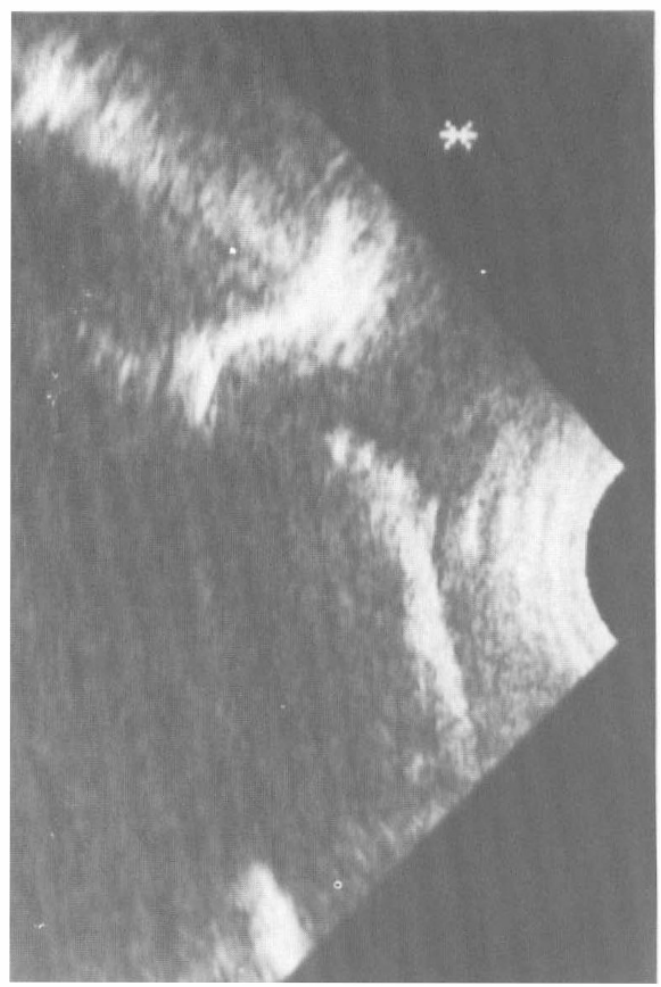

f

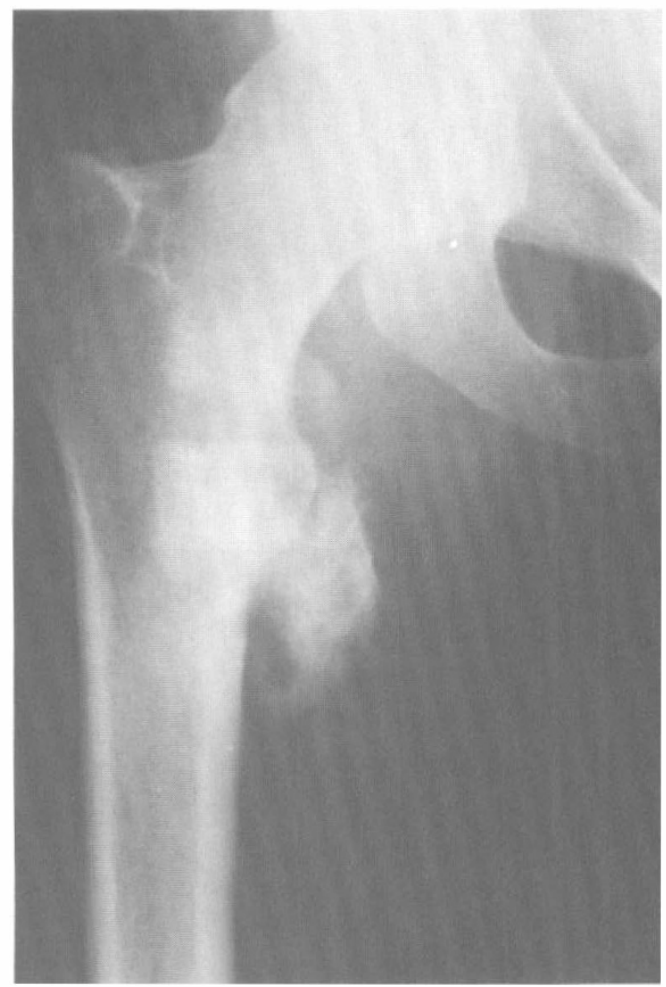

Figure $2(a, b)$ Early sonographic detection of thigh HBF with compression of the femoral vein seen at venography. (c, d) Although plain radiographs confirm the lesion 2 weeks later, sonography at this time reveals extension of the lesion proximal and distal to the lesser trochanter, which is later confirmed by a further radiograph at 8 weeks $(e, f)$.

\section{Discussion}

Primitive mesenchymal derived cells differentiate into bone forming cells within soft tissue in response to a variety of stimuli. ${ }^{5}$ Previously known as 'myositis ossificans circumscripta' this soft tissue response is now more accurately described as heterotopic bone formation (HBF). The lesion is characterised by an initial soft tissue inflammatory phase followed by heterotopic ossification. Stover et $a l^{6}$ reported an $\mathrm{HBF}$ incidence of $30 \%$ in spinal injury patients while most authors cite an incidence $15-20 \% .^{2.7 .8}$ The heterotopic bone formation causes considerable morbidity due to swelling, pain, and loss of range of movement of the affected extremity which result in delay in the rehabilitation. The early clinical features are pain, warmth and oedema of surrounding soft tissue with occasional fever and an elevated ESR. These clinical features of the early inflammatory phase and resultant extremity swelling mimic deep venous thrombosis, cellulitis, osteomyelitis, abscess, a developing pressure sore and tumour. ${ }^{8,9}$ At this early stage the initial radiographic features are non specific and even if the correct diagnosis is suspected, confirmation depends on an expectant policy requiring 4-6 weeks for the ossification to be diagnostic radiologically. In a study by Orzell \& Rudd ${ }^{9}$ over half of the patients had an original clinical diagnosis of deep venous thrombosis and the initial radiological investigation requested was a venogram. A firm diagnosis of $\mathrm{HBF}$ can be made sonographically before there are any radiographic abnormalities and when the clinical signs and symptoms are at a peak. Sequential examinations during maturation 
a

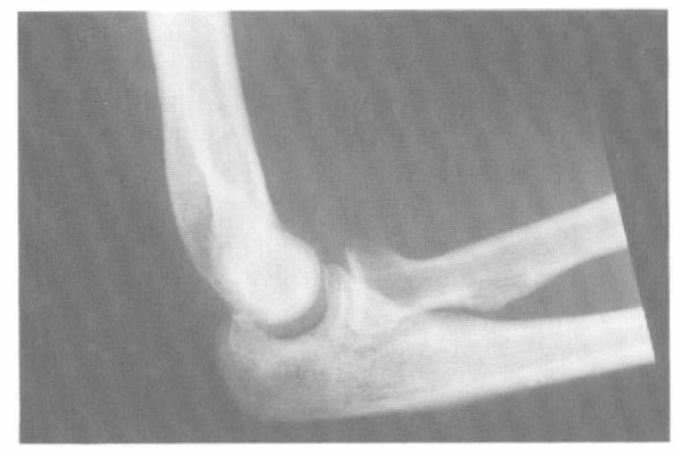

b

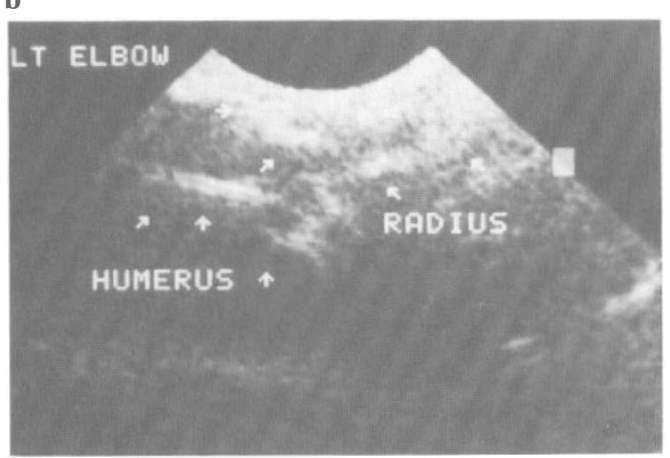

c

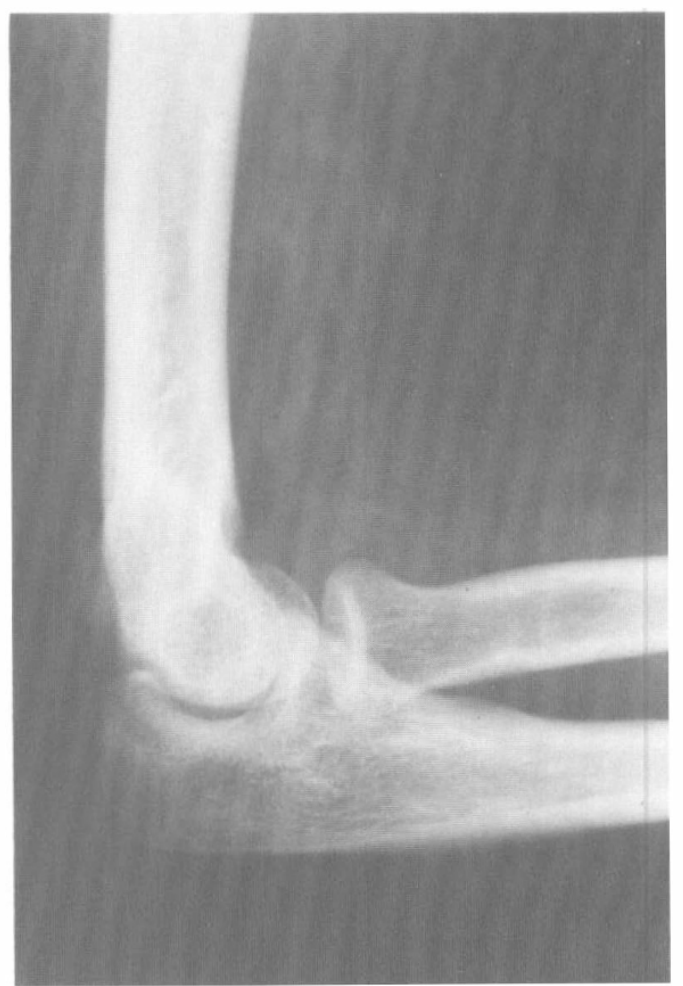

Figure 3 Elbow HBF (case I). (a) Postreduction lateral elbow radiograph fails to reveal any evidence of $\mathrm{HBF}$ while (b) sonography shows an HBF lesion anterior to the elbow joint (arrows) which is conformed (c) 4 weeks later by plain radiography.

of HBF will indicate the optimum time for plain radiography which minimises the radiation dosage.

Irrespective of the initiating stimulus, heterotopic bone formation passes through the same histological phases and processes. Initially microscopic examination shows areas of muscle necrosis and haemorrhage with fibroblastic proliferation, which appears radiographically as soft tissue swelling without calcification or ossification. The centrifugal pattern of maturation that is seen in the ensuing weeks is the basis of the low field pathological description of 'zone phenomenon', described by Ackerman ${ }^{3}$ and Johnson. ${ }^{4}$ In the central zone there is an undifferentiated highly cellular proliferation with haemorrhage and muscle necrosis. In the intermediate zone there are areas of immature bone lined by osteoblasts while in the outer zone mature bone is present forming a well demarcated outer trabecular rim (Fig 6). The primitive osteoid is laid down early within the first 2 weeks always, to begin with at the periphery, because within this region maturation is at its most advanced. The osteoid is deposited first as small masses within the fibroblastic mesenchymal peripheral reaction (Figs 2, 3). ${ }^{10}$ The muscle fibres and soft tissues around the lesion can appear compressed but the interface is smooth and there is no evidence of invasion. This zoning pattern of peripheral maturation is the most important diagnostic feature and is present in both the traumatic and the non traumatic types of heterotopic bone formation..$^{3,4,11-14}$ The zone phenomenon was demonstrated sonographically in all of the patients at presentation, indicating that clinical symptoms occur 
a

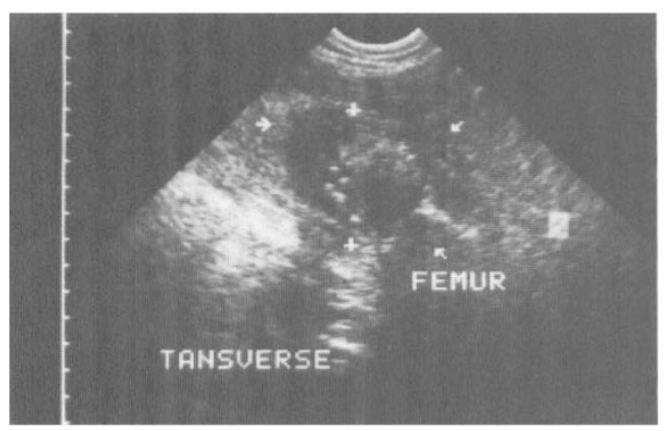

b

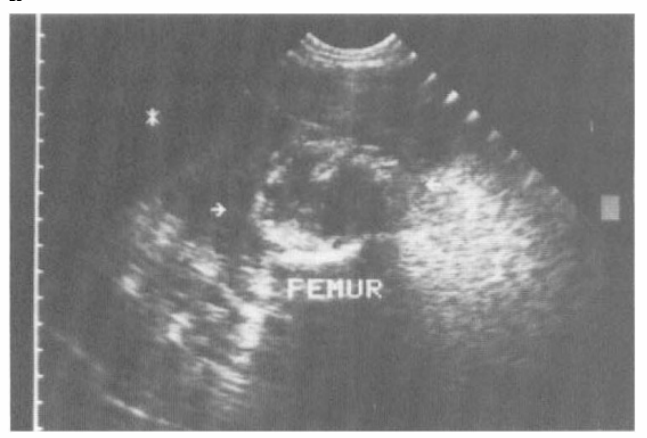

c

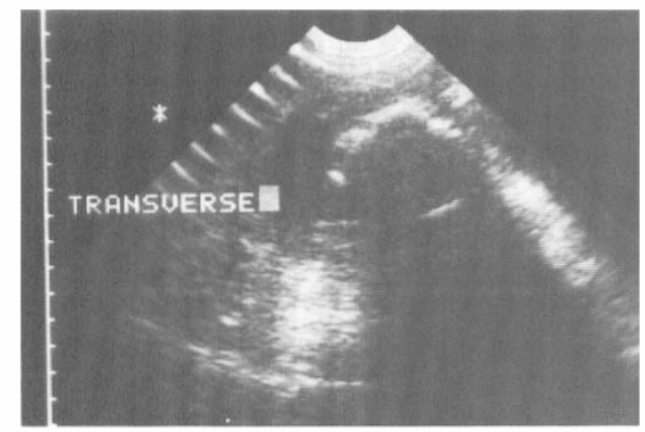

Figure 4 Sonographic evolution of the HBF lesion in the thigh imaged in the transverse plane. (a) Peripheral sonolucent zone surrounds a mineralized middle zone with sonolucent inner zone. The plain radiographs were normal. (b) 3 weeks later showing increased density of mineralised layer but lesion still allows ultrasound transmission to highlight attachment to femur. (c) 6 weeks after presentation with mature periphery of lesion causing total reflection of ultrasound beam. at a stage when zone transformation can be demonstrated sonographically, thus permitting an early diagnosis.

The appearance of the lesion can be influenced by mechanical forces and in particular the peripheral zone may be remodelled in the axis of the forces of muscle traction. It is not uncommon, initially to sonographically demonstrate an incomplete ring of ossification in the outer zone of the lesion which later becomes complete (Figs 3, 4). An abscess can also be associated with rapid growth as well as pain and swelling. Sonography easily demonstrates the nature of the fluid consistency, the abscence of a zonal phenomenon, and also permits sonographically guided needle aspiration to confirm the nature of the lesion. Sonography also has the capability of differentiating HBF from a soft tissue sarcoma which although rare in this clinical setting must be considered. Furthermore, newer advances in sonographic technology allow the demonstration of thrombosis in the affected veins.

Alternative methods of early diagnosis include plain radiography, scintigraphy and serial estimations of alkaline phosphatase. Floccular calcification can be recognised in plain radiographs by the fourth week but the timing of these appearance varies considerably ${ }^{15,16}$ and occurs at a relatively late stage when the inflammatory clinical manifestations subside. In recent times, with computed tomography it has been possible to demonstrate the diagnostic features of the zone phenomenon. ${ }^{17}$

Radionuclide bone imaging has been utilised in the evaluation of $\mathrm{HBF}$ and 3-phase imaging has been advocated for the early diagnosis and serial monitoring of disease activity. ${ }^{18,19}$ Scintigraphy enjoys a high sensitivity but with a low specificity in making a diagnosis of HBF. The sensitivity of a rising serum alkaline phosphatase as an indicator of HBF has been a matter of some dispute in the literature. Serum alkaline phosphatase levels were originally reported to be normal in heterotopic bone formation, ${ }^{20}$ but later studies showed that these were invariably abnormal, rising at the time of radiographic appearances of soft tissue calcification. ${ }^{21,22}$ Orzell \& $\operatorname{Rudd}^{9}$ in a study of scintigraphy, 


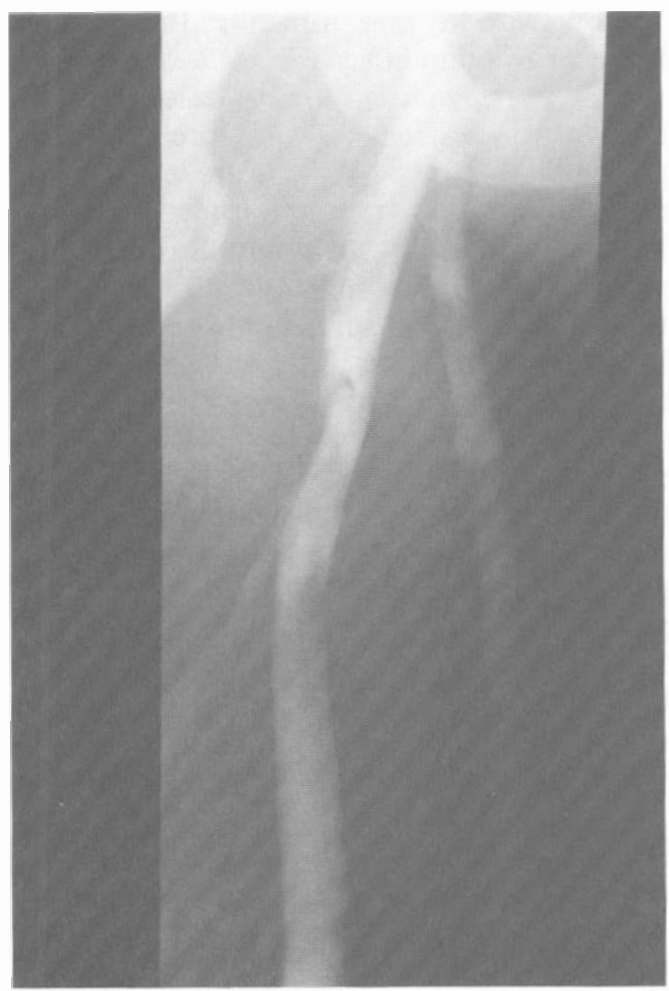

b

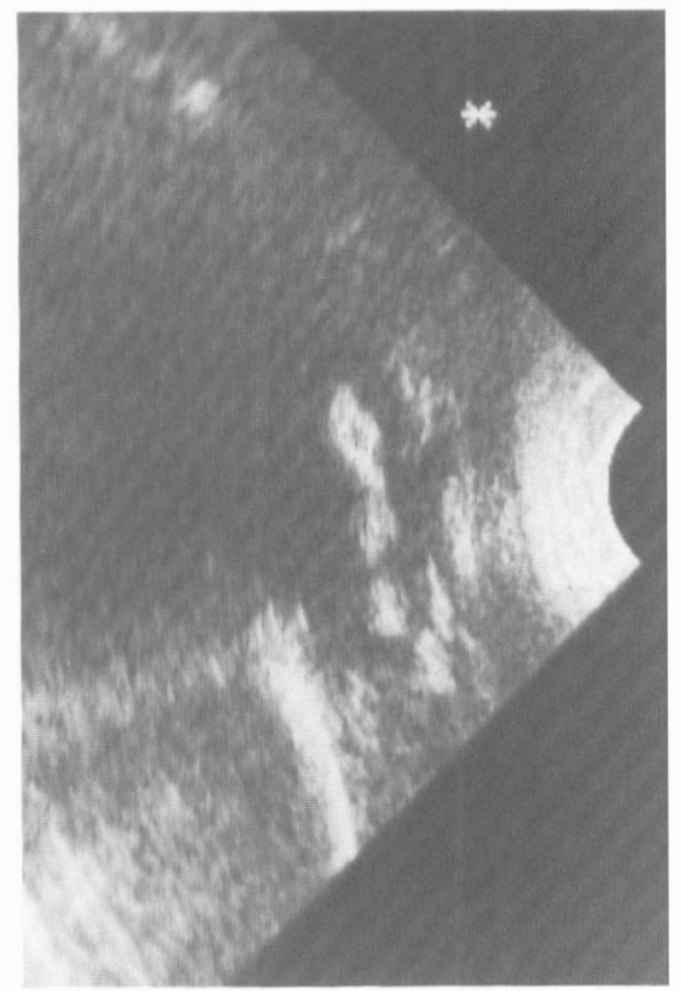

Figure 5 (a, b) Extrinsic compression of the femoral vein by HBF in the proximal thigh confirmed sonographically.

plain radiography and serum alkaline phosphatase in 43 patients with HBF, $27(63 \%)$ of whom had a spinal cord injury, found the latter to be a sensitive indicator of early HBF rising well in advance of symptoms and radiographic soft tissue calcification. However scintigraphic demonstration of HBF can occur when the serum alkaline phosphatase is within normal limits although rising. In our series the serum alkaline phosphatase level was normal in all of the patients at the time of the sonographic diagnosis of $\mathrm{HBF}$, and in only 3 of the patients subsequently rose to abnormal SAP levels. Furthermore, the elevation of SAP is not specific to HBF and may be consequent to healing fractures in the axial and peripheral skeleton, occult biliary disease, or normal bone growth in younger patients. Like Orzell \& Rudd we found that when present a rasied serum alkaline phos- phatase was ignored because it was not specifically requested but was measured incidently along with the more urgent laboratory tests requested. This should be deprecated, as the detection of a raised or rising serum alkaline phosphatase requires prompt sonographic exclusion of $\mathrm{HBF}$ in common sites such as the hip and knee regions. This would permit early diagnosis and would provide a base line study on which to assess response to therapy.

$\mathrm{HBF}$ may result in an aggravation of the patient's disability, prevention of passive movement, joint ankylosis and increased limb spasm, with an increased potential for the development of pressure sores. However oral diphosphonate therapy and more recently nonsteroidal antiinflammatory drugs can modify the process of heterotopic ossification quite significantly, and the early diagnosis prior to the radiographic 


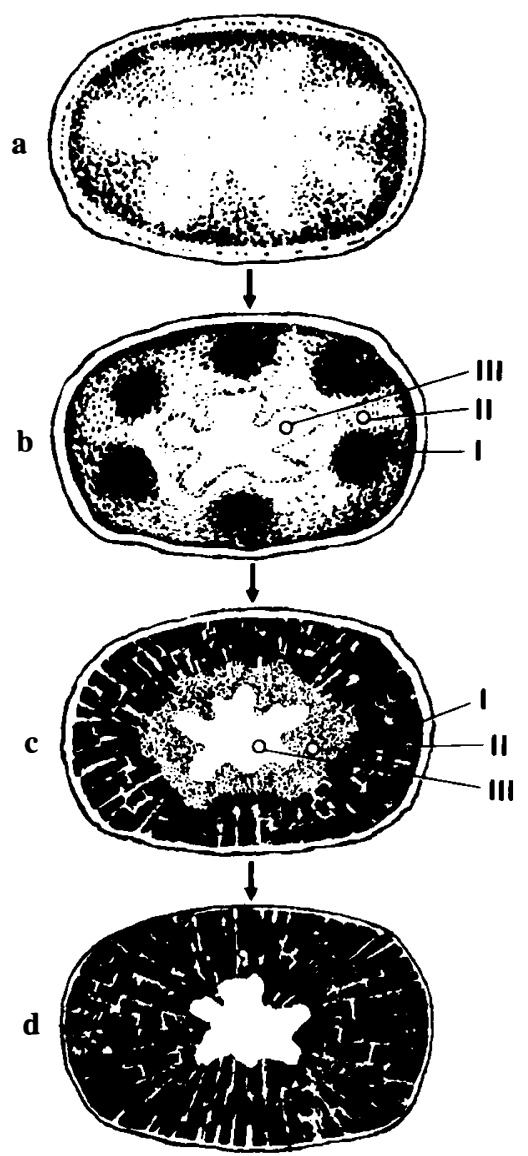

Figure 6 Pathology, evolution and maturation of HBF. (a) Peripheral mesenchymal cell stimulation with inward migration towards central core which contains haemorrhage fibrin and necrosis. (b) 'Zone phenomena' formation: osteoid and bone first laid down in periphery zone I, encompassing the less mature partially mineralised zone II, with immature inner zone III containing active fibroblastic proliferation. (c) Centripetal maturation with consolidation of the 3 zones to yield (d) mature woven bone with marrow cavity. demonstration of ossification can therefore have therapeutic implications. Diphosphonates are potent inhibitors of calcification ${ }^{23}$ and if treatment is to be effective it should be ideally instituted before radiographic evidence of HBF. ${ }^{9}$ If such therapy is to be used, it should start at the first symptom of disease with the demonstration of the early HBF lesion sonographically. Following the diagnosis and the institution of oral therapy, sonography can monitor the response to treatment. Previous case reports of the sonographic demonstration of the HBF lesion have described varied appearances: an echo free mass with central calcification, ${ }^{24}$ generalised muscle swelling with lamellar calcification, ${ }^{25}$ and the soft tissue mass without the triple zone phenomenon. ${ }^{26}$ There is no mention of the zone phenomena seen in all our cases which closely parallels the histological pattern of maturation. The reasons for this are unclear but may reflect the lack of sequential scans and time sequence of obtaining the ultrasound examination. No lesion which was eventually demonstrated radiographically was missed by sonography. Sonography is a cheap, quick and easy imaging modality with a high predictive negative value for the confirmation or the exclusion of HBF setting of limb inflammation.

\section{Acknowledgements}

We would like to thank Miss Tina Williams for typing the manuscript and the Medical Photographic Department for the photographic prints.

\section{References}

1 Riedel B (1883) Demonstration eines durch achttagiges Umhergehen total destruirten kniegelenkes von einem Patienten mit Stichverletzung des Ruckens. Verhandlungen der Deutschen Gesellschoft fur Chirurgie 12: 93.

2 Hardy AG, Dickson JW (1963) Pathological ossification in traumatic paraplegia. J Bone Joint Surg 45B: 76-87.

3 Ackerman LV (1958) Extra-osseous localized non-neoplastic bone and cartilage formation. (So-called myositis ossifications). J Bone Joint Surg 40 A: 279-298.

4 Johnson LC (1948) Histogenesis of myositis ossificans. Am J Pathol 24: 681-682.

5 Buring K (1975) On the origin of cells in heterotopic bone formation. Clin Orthopaed 110: $293-302$. 
6 Stover SL, Niemann KMW, Miller JM (1976) Disodium etidronate in the prevention of post-operative recurrence of heterotopic ossification in spinal cord injury patients. J Bone J Surg 58A: 683-688.

7 Silver JR (1969) Heterotopic ossification. A clinical study of its possible relationship to trauma. Paraplegia 7: $220-230$

8 Wharton GW, Morgan TH (1970) Ankylosis in the paralyzed patient. J Bone Joint Surg 52A: 105-112.

9 Orzell J, Rudd T (1985) Heterotopic bone formation: Clinical, laboratory and imaging correlation. $J$ Nucl Med 26: 125-132.

10 Mirra JM (1989) Bone Tumours. Vol 2. Lea \& Febiger, Philadelphia: 1549-1586.

11 Gilmer W Anderson L (1959) Reactions of soft somatic tissue which may progress to bone formation: Circumscribed (traumatic) myositis ossificans. South Med J 52: 1432-1448.

12 Lagier R, Cox JN (1975) Pseudomalignant myositis ossificans. A pathological study of eight cases. Hum Pathol 6(6): 653-656.

13 Angervall L, Stener B, Stener I (1969) Pseudomalignant osseous tumour of soft tissue. A clinical, radiological and pathological study of five cases. J Bone Joint Surg 51B(4): 654-663.

14 Thomas EA, Cassar-Pullicino VN, McCall IW (1991) The role of ultrasound in the early diagnosis and management of heterotopic bone formation. Clin Radiol 43: 190-196.

15 Norman A, Dorfman HD (1970) Juxta-cortical circumscribed myositis ossificans: Evolution and radiographic features. Radiology 96: 301-306.

16 Goldman AB (1976) Myositis ossificans circumscripta: A benign lesion with a malignant differential diagnosis. Am J Radiol 126: 32-40.

17 Amendola MA, Glazer G, Agha FP, Francis I, Weatherbee L, Martel W (1983) Myositis ossificans circumscripta: computed tomographic diagnosis. Radiology 149: 775-779.

18 Freed HH, Dreisbach JN, Hahn H, Enneking WF, Springfield DS Andrew ER et al (1981) The use of the three phase bone scan in the early diagnosis of heterotopic ossification (HO) and in the evaluation of Didronel therapy. Proceedings of the Seventh Annual Scientific Meeting of the American Spinal Injury Association. March 26-30 1981, New Orleans: 63-64.

19 Suzuki Y, Hisada K, Takeda M (1974) Demonstration of myositis ossificans by $99 \mathrm{mTC}$ pyrophosphate bone scanning. Radiology 111: 663-664.

20 Venier LH, Ditunno JF Jr (1971) Heterotopic ossification in the paraplegic patient. Arch Phys Med Rehabil 52(10): 475-479.

21 Furman R, Nicholas JJ, Jivoff L (1970) Elevation of the serum alkaline phosphatase coincident with ectopic-bone formation in paraplegic patients. J Bone Joint Surg 52A: 1131-1137.

22 Nicholas JJ (1973) Ectopic bone formation in patients with spinal cord injury. Arch Phys Med 54: 354-359.

23 Finerman GAM, Stover SL (1981) Heterotopic ossification following hip replacement or spinal cord injury. Two clinical studies with EHDP. Metab Bone Dis Rel Res 4(5): 337-342.

24 Kramer K, Kurtz A, Rubin C, Goldberg BA (1979) Ultrasound appearance of myositis ossificans. Skel Radiol 4: 19-20.

25 Peck RJ, Metreweli C (1988) Early myositis ossificans: A new echographic sign. Clin Radiol 39: 586-588.

26 Kirkpatrick JS, Koman LA, Rouere GD (1987) The role of ultrasound in the early diagnosis of myositis ossificans. Am J Sports Med 15: 179-181. 